\title{
Percutaneous reduction of mitral valve regurgitation using the MitraClip system - immediate and 90-day follow-up of 3 cases
}

\author{
Piotr Kübler ${ }^{1}$, Dorota Kustrzycka-Kratochwil', Artur Telichowski ${ }^{1}$, Tomasz Witkowski ${ }^{1}$, Waldemar Banasiak ${ }^{1}$, \\ Ewa A. Jankowska ${ }^{1,2}$, Piotr Ponikowski ${ }^{1,2}$, Krzysztof Reczuch ${ }^{1,2}$
}

1Department of Cardiology, Military Clinical Hospital, Wroclaw, Poland

2Department of Heart Diseases, Medical University of Wroclaw, Poland

Postep Kardiol Inter 2013; 9, 2 (32): 126-131

DOI: $10.5114 /$ pwki.2013.35446

\begin{abstract}
Treatment of hemodynamically significant valvular heart diseases has been the domain of cardiac surgery for decades. However, a promising novel method is the MitraClip system, involving percutaneous connection of insufficient valve leaflets with special cobalt-chrome clips. Our study presents clinical characteristics, course of treatment with the MitraClip system, and immediate and 90-day clinical and echocardiographic follow-up of the first 3 patients treated in our institution. Subsequently, based on data from the literature and our own experience, the current position around the world, and the target group of patients who are most likely to benefit from treatment using the MitraClip system, are discussed.
\end{abstract}

Key words: severe mitral regurgitation, MitraClip system.

\section{Introduction}

Mitral regurgitation (MR) is the most common disease of the mitral valve and the second most common valvular heart disease after aortic stenosis. The MR of at least moderate degree is present in $15-30 \%$ of patients with congestive heart failure and in up to $12 \%$ of patients who underwent myocardial infarction during the preceding month [1]. Its incidence increases with age, which becomes more and more important due to the aging of the general population [2]. The most frequent causes of MR include degenerative changes of the valvular apparatus and functional MR in the course of ischemic heart disease and cardiomyopathy. Additionally, MR may be caused by infective endocarditis or rheumatic fever. For many years cardiac surgery has been the only method of treatment of hemodynamically significant valvular heart diseases, including mitral valve diseases. New valvular prostheses, meticulous surgical techniques, including a variety of repair procedures and minimally invasive treatments and years of experience of the operators guarantee low morbidity and mortality. However, the development and miniaturization of the equipment, similar to the one observed for aortic valve procedures, per- mit the use of less invasive techniques also for the treatment of the mitral valve. Additionally, almost $1 / 3$ of patients with $M R$ are at high risk of surgery caused mainly by the advanced age, impaired left ventricular function and the presence of comorbidities [3].

All-cause mortality after surgical procedures on the mitral valve in patients above 75 years of age undergoing concomitant bypass grafting reaches $14 \%$ [4]. This is an additional stimulus for the development of alternative forms of therapy and indicates a target group which may benefit from them. Intensive development of non-surgical techniques of MR treatment and transluminal interference into the complicated structure of the mitral apparatus, which is more complex than the aortic apparatus, has only been possible for the last few years. Some techniques, such as introduction of systems aimed at restoration of normal mitral annulus diameter through the coronary sinus, did not fully bring the expected results and are still at the early clinical phase. A new promising method is the MitraClip system, the idea of which is derived from the surgical technique proposed by Alfieri in the year 1991 [5]. The procedure is based on transluminal connection of the regurgitant mitral valve leaflets by

\section{Corresponding author:}

Piotr Kübler MD, PhD, Department of Cardiology, Military Clinical Hospital, 5 Weigla St, 50-981 Wroclaw, Poland, tel./fax: +48 717660250 ,

e-mail: pkubler75@gmail.com

Received: 17.02.2013, accepted: 9.05.2013. 
means of one (or less frequently more) dedicated cobaltchromium clips. Connected leaflets form a dual and reduced valvular orifice and the mitral valve becomes a doubleorifice valve. The procedure is performed in the hybrid catheterization laboratory or in the catheterization laboratory under general anesthesia (although it is possible to perform a procedure under sedation and local anesthesia) and with fluoroscopic and transesophageal echocardiographic control. A multidisciplinary team consists of 2 interventional cardiologists, a person performing echocardiography, an anesthesiologist and trained nurses. The procedure has been used for patients with degenerative and functional forms of MR. Feldman et al. were the first to report the results of the first procedures using the MitraClip system in humans [6]. Detailed methodology and the first positive Polish results of the in-hospital observation were presented by the center in Zabrze in 2010 [7] and the role of echocardiography, which is crucial for qualification and monitoring of the MitraClip procedures, was described by the authors from Bydgoszcz [8]. We present direct and 90-day results of treatment of the first 3 patients in our center.

\section{Case report}

Three patients qualified for the procedure using the MitraClip in our center had a severe post-myocardial infarction heart failure (NYHA class III or IV) with enlarged left ventricle and coexisting significant functional MR (Table 1). Concomitant diseases worth mentioning included chronic renal failure stage 3 in all patients, chronic atrial fibrillation in 2 patients, diabetes mellitus, hepatic cirrhosis and pancytopenia caused by hypersplenism in 1 patient. In all pa- tients the surgical risk of MR treatment was considered high. The procedures were performed in the catheterization laboratory under general anesthesia with cardiac surgeons and operating room on-call. The system for inter-atrial septal puncture with the Mullins sheath and the Brockenbrough needle was introduced through the right femoral vein and inferior vena cava. The inter-atrial septum was punctured under transesophageal echocardiography control at its upper part and high enough to permit correct introduction of the Guide Catheter and the MitraClip system with the clip to the left atrium perpendicularly to the orifice plane of the mitral valve (Figure 1). The next steps required precise imaging by means of transesophageal echocardiography as presented in Figure 2. The Guide Catheter with open clips was placed axially in the mitral valve orifice and then introduced below the level of the leaflet coaptation in the central part of the regurgitant jet (Figure 3). Retraction of the system permitted two leaflets to be caught and the clip to be closed. This stage of the procedure might have been repeated in order to optimally catch the leaflets. After obtaining a satisfactory effect on echocardiographic assessment a closed clip was released (Figure 4) and the system was removed from the body. The mean time of the procedure was $5 \mathrm{~h}$ and $40 \mathrm{~min}$ ( 4 to 6 and a half $h$ ) with a mean fluoroscopy time of $36 \mathrm{~min}$ (34-37 min). One patient suffered from lower respiratory tract infection in the post-procedural phase, which required therapy with antibiotics. No local vascular complications or deterioration of renal failure were observed. There was an improvement of exercise capacity assessed by NYHA class and a mild increase of LVEF in all patients at 3 months after the procedure (Table 2). In 2 patients a sig-

Table 1. Clinical and echocardiographic characteristics of patients undergoing MitraClip implantation

\begin{tabular}{|c|c|c|c|}
\hline Variable & Patient 1 & Patient 2 & Patient 3 \\
\hline Age [years] & 62 & 78 & 59 \\
\hline Sex & M & $\mathrm{F}$ & $M$ \\
\hline \multirow[t]{2}{*}{ Coronary artery disease } & $\begin{array}{l}1 \times \text { myocardial } \\
\text { infarction }\end{array}$ & $\begin{array}{c}1 \times \text { myocardial } \\
\text { infarction }\end{array}$ & $\begin{array}{c}1 \times \text { myocardial } \\
\text { infarction }\end{array}$ \\
\hline & $2 \times \mathrm{PCl}$ & $1 \times \mathrm{PCl}$ & $\begin{array}{c}1 \times C A B G \\
3 \times P C l\end{array}$ \\
\hline Logistic EuroSCORE [\%] & 19.2 & 30.2 & 36.2 \\
\hline ECG & Sinus rhythm, LBBB & AF, LBBB & AF \\
\hline Type of regurgitation according to Carpentier & I, IIIB & I, IIIB & I, IIIB \\
\hline Etiology of the regurgitation & Ischemic & Ischemic & Ischemic \\
\hline Effective regurgitant orifice area $\left[\mathrm{cm}^{2}\right]$ & 0.4 & 0.4 & 0.5 \\
\hline Vena contracta width [mm] & 7 & 7 & 7 \\
\hline Regurgitant volume [ml] & 60 & 45 & 86 \\
\hline Mitral annulus diameter [mm] & 38 & 38 & 39 \\
\hline Leaflet coaptation depth [mm] & 10.5 & 10 & 7.5 \\
\hline Leaflet coaptation length [mm] & 2.5 & 2.5 & 2.6 \\
\hline
\end{tabular}

$A F$ - atrial fibrillation, $C A B G$ - coronary artery bypass grafting, $L B B B$ - left bundle branch block, $F$-female, $M$ - male, $P C I$ - percutaneous coronary intervention 


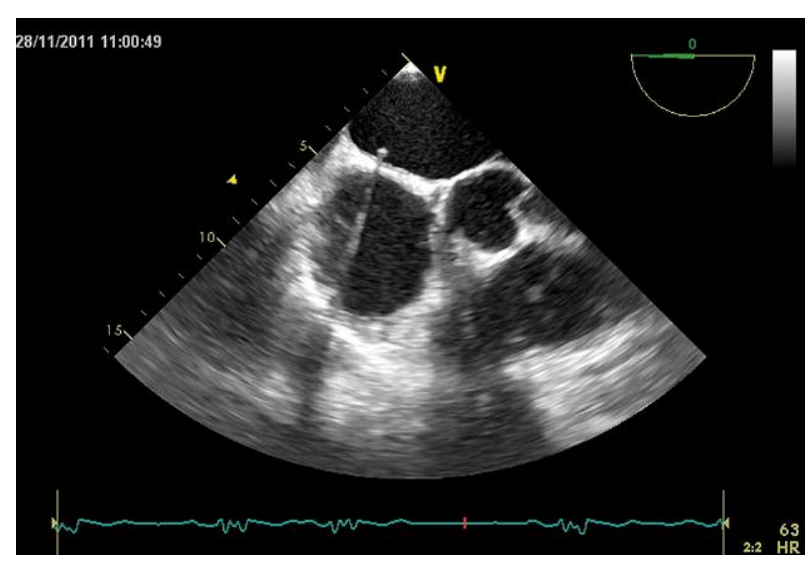

Fig. 1. Puncture of the inter-atrial septum visible on transesophageal echocardiography

nificant reduction of the MR degree and pulmonary hypertension were noted (Figures $5 \mathrm{~A}, \mathrm{~B}$ ). In 1 patient quite severe mitral regurgitation persisted despite fixation of two leaflets by the clip (Figures 5 C, D). The effect of this procedure has to be considered as non-optimal despite a subjective improvement of exercise capacity reported by the patient. The patient has been considered as a potential candidate for the introduction of a second clip. In addition, during 3 months of observation 1 patient suffered from decompensated heart failure caused by an episode of atrial flutter with rapid ventricular rhythm, which was successfully treated with pharmacotherapy.

\section{Discussion}

In recent years there has been dynamic development of percutaneous techniques used to treat structural heart diseases, including those involving the mitral valve. Currently, the key question is which patients will benefit most from percutaneous treatment of significant MR and how to select this group. The first broader experience was obtained from the American EVEREST study and its continuation, EVEREST II, in which patients with significant MR suitable for percutaneous and surgical treatment were randomized to one of those methods [9]. Anatomic criteria included LVEF $>25 \%$, left ventricular end-systolic diameter $<55 \mathrm{~mm}$, mitral valve orifice area $>4 \mathrm{~cm}^{2}$, central regurgitation jet related to $A 2 / P 2$ segment of the valve, coaptation length $\geq 2 \mathrm{~mm}$, and coaptation depth $\leq 11 \mathrm{~mm}$. The main result at 2 years was that percutaneous treatment is significantly less effective in reduction of regurgitation, but safer than surgery and equally effective in terms of clinical assessment. One of the arms of this study, EVEREST II HRS, focused on patients at the highest risk of surgery including those with impaired left ventricular systolic function, which was a population similar to the 3 cases presented here. A control group consisted of patients with similar clinical char-

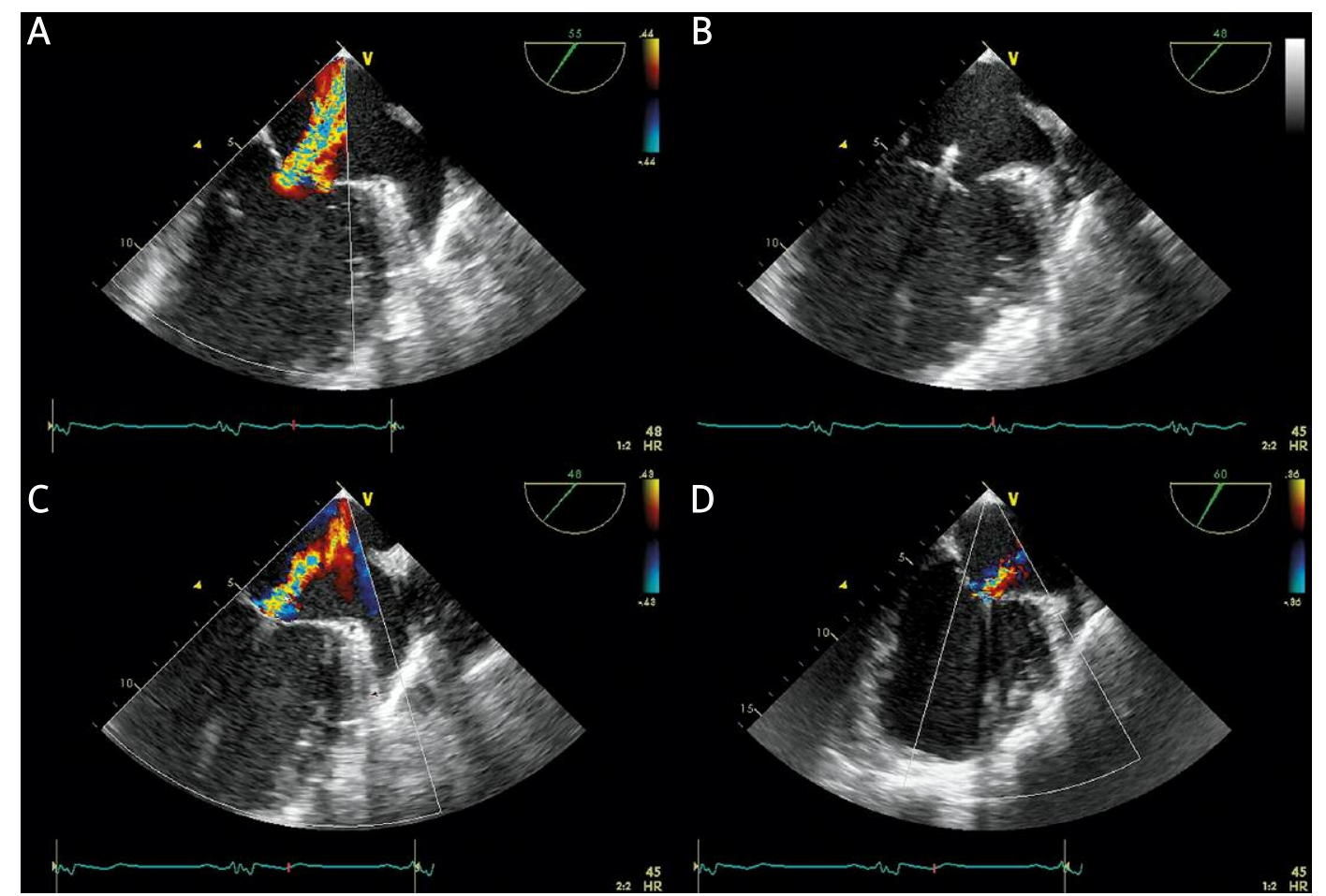

Fig. 2. Successive steps of MitraClip implantation visible on transesophageal echocardiography: A - Visible initially large regurgitant jet across the mitral valve. B - Placement of the MitraClip system axially to the mitral orifice. C - Catching of the two valvular leaflets by the clip. D - Reduction of the regurgitant jet after closure of the clip and retraction of the MitraClip system 


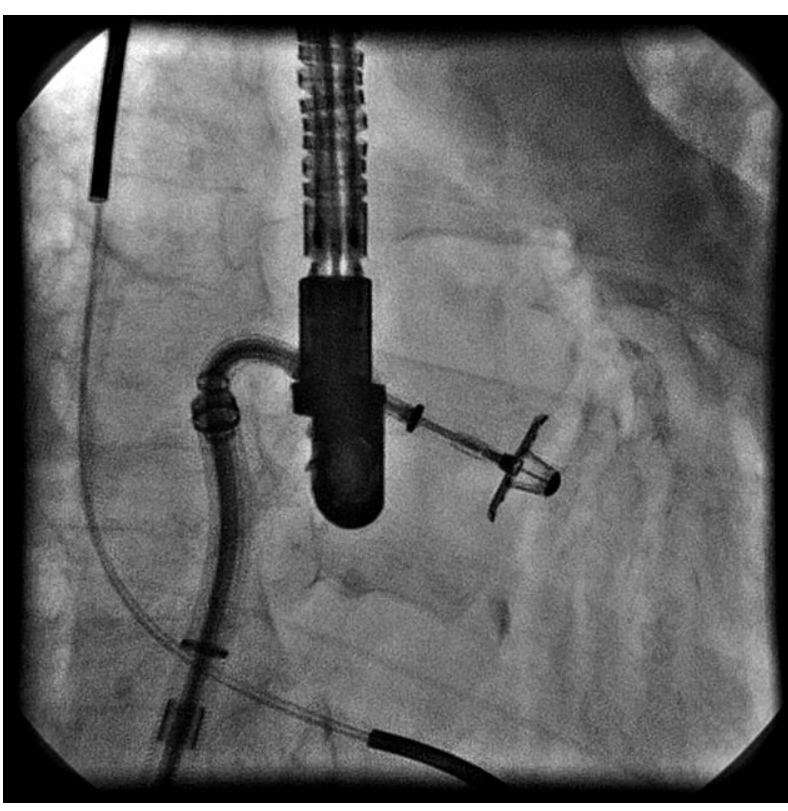

Fig. 3. The MitraClip system at the level of the mitral valve during positioning

acteristics, who were not included in the study [10]. At 1 year patients who received a clip had higher survival in comparison to those treated conservatively ( $76 \%$ vs. $55 \%)$ and better exercise capacity with maximal MR of $2^{\text {nd }}$ degree achieved in $78 \%$ of patients. A reduction of left ventricular end-systolic and end-diastolic volume was also observed. However, this was not a randomized clinical trial. The European experiences come mainly from the German and Italian registries and the largest international ACCESS-EUROPE registry, whose initial results were presented during the congress of the European Society of Cardiology in 2012. In the registry conducted by Franzen et al. 51 patients who qualified for treatment with the MitraClip had severe MR and high risk of surgery (logistic EuroSCORE > 20, STS score >12) with relatively few inclusion criteria in comparison to the EVEREST trial. Implantation of the MitraClip was success-

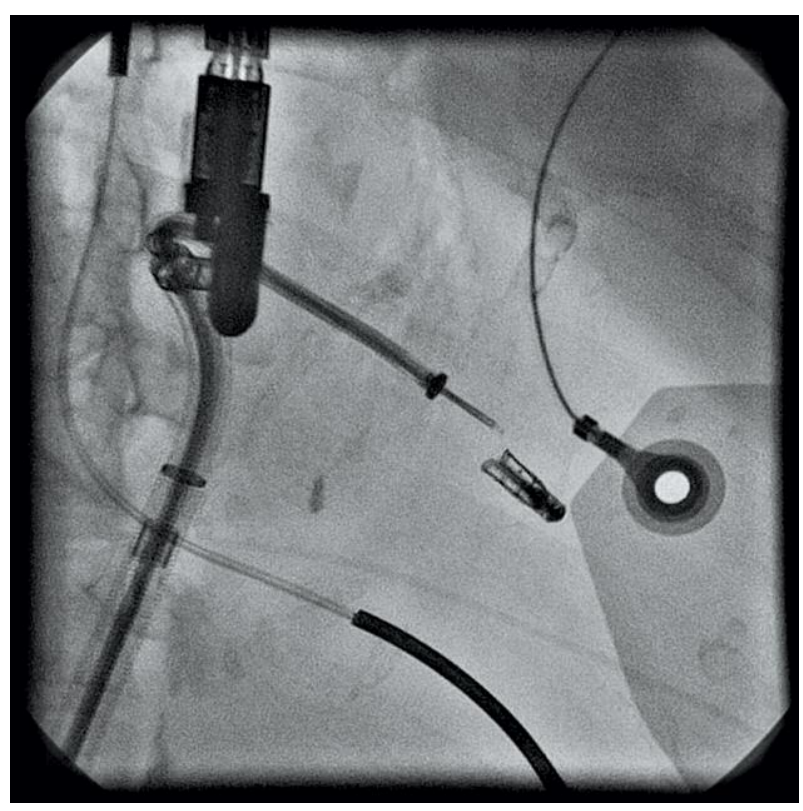

Fig. 4. The clip released from the delivery set fixing the leaflets of the mitral valve

ful in $96 \%$ of patients with post-procedural MR reduction by at least 1 degree in 31\% of patients, by 2 degrees in $47 \%$ and by 3 degrees in 18\% [11]. The largest German registry included 481 patients, $93 \%$ of them in NYHA class III or IV, with mean logistic EuroSCORE of $23 \%$. The MR reduction to mild or moderate degree was achieved in $94 \%$ of patients, exercise capacity improvement to NYHA class I or II after a mean of 85 days was observed in $64 \%$ of patients, and mortality rate was $12.5 \%$ [12]. Tamburino et al. presented results of treatment of significant MR with MitraClip implantation in a group of 31 patients also at high risk of classic surgery. All procedures were successful and significant complications consisted of 1 cardiac tamponade and 1 noncardiac death. At 30 days there was beneficial remodeling of the left ventricle with reduction of the mitral annulus diameter on echocardiography [13]. The ACCESS-EUROPE registry

Table 2. Clinical and echocardiographic results of 90-day observation after MitraClip implantation

\begin{tabular}{|c|c|c|c|c|c|c|}
\hline \multirow[t]{2}{*}{ Variable } & \multicolumn{2}{|c|}{ Patient 1} & \multicolumn{2}{|c|}{ Patient 2} & \multicolumn{2}{|c|}{ Patient 3} \\
\hline & Before & 90 days & Before & 90 days & Before & 90 days \\
\hline NYHA class & III & II & III/IV & $\| / I I I$ & III & II \\
\hline LVEF [\%] & 18 & 25 & 28 & 30 & 25 & 30 \\
\hline LVEDD [mm] & 72 & 72 & 70 & 63 & 64 & 62 \\
\hline LVEDV $[\mathrm{ml}]$ & 265 & 233 & 217 & 185 & 200 & 201 \\
\hline Regurgitant jet & +++ & $+/++$ & $+++/++++$ & ++ & +++ & $++/+++$ \\
\hline Diastolic mitral gradient [mm Hg] & & $5 / 2$ & & $7 / 2$ & & $8 / 3$ \\
\hline Valvular area in diastole (planimetric) [ $\left.\mathrm{cm}^{2}\right]$ & 6.2 & 3.6 & 5.0 & 1.5 & 5.1 & 1.4 \\
\hline Systolic tricuspid gradient [mm Hg] & 62 & 38 & 32 & 23 & 32 & 28 \\
\hline $\mathrm{RAP}[\mathrm{mm} \mathrm{Hg}]$ & 15 & 15 & 15 & 8 & 15 & 15 \\
\hline
\end{tabular}

LVEF - left ventricular ejection fraction, LVEDD - left ventricular end-diastolic diameter, LVEDV - left ventricular end-diastolic volume, NYHA - New York Heart Association, RAP - right atrial pressure 


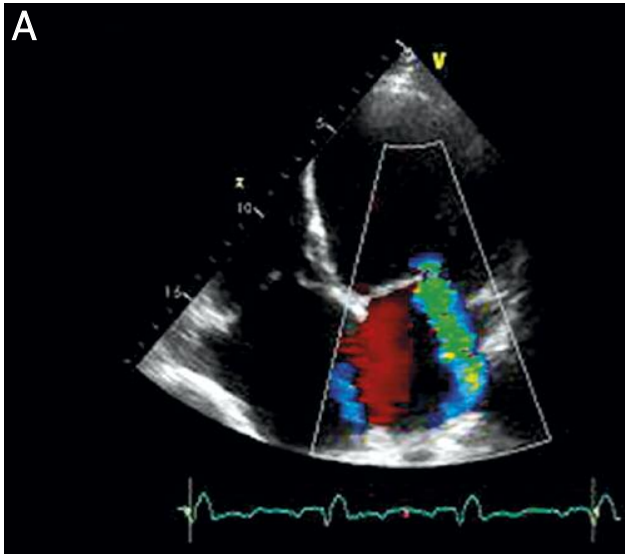

C

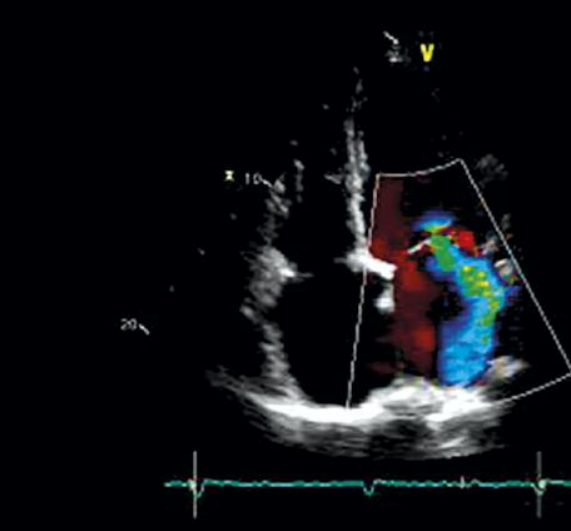

B

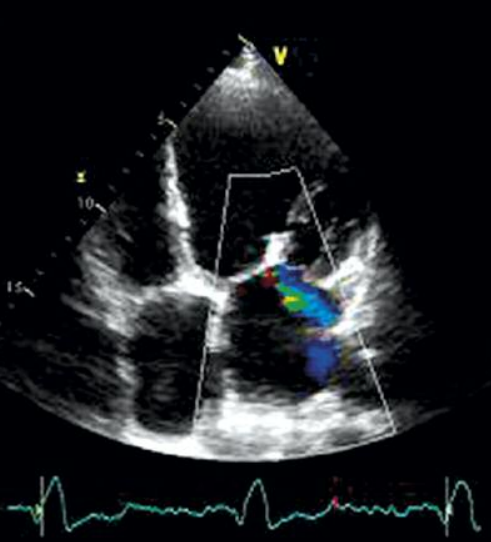

D

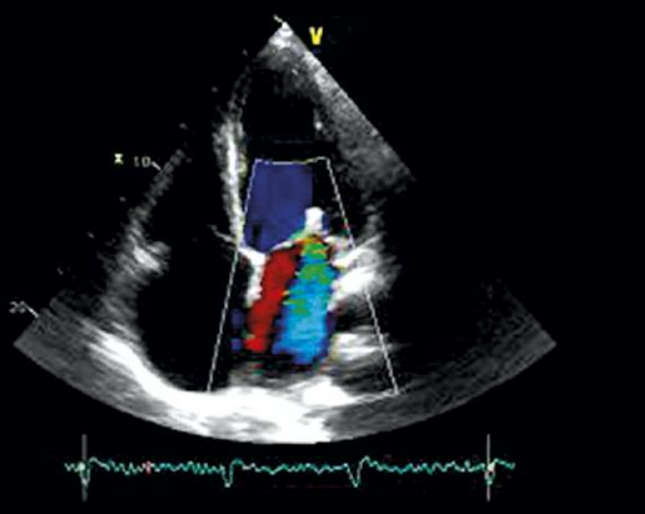

Fig. 5. Comparison of the mitral regurgitation range before the procedure and 90 days after the procedure of MitraClip implantation. A, B - Good effect of the procedure. C, D - Non-optimal effect of the procedure

included a total of 567 patients age $74 \pm 10$ years mostly with numerous concomitant diseases (logistic EuroSCORE 23 $\pm 18 \%$ ) from 14 European centers. One-year survival after MitraClip implantation was $82 \%$ with the majority of patients reporting clinical improvement - NYHA class I/II in $72 \%$ of patients, 6-minute walk distance increased by a mean of $60.5 \mathrm{~m}$, and $79 \%$ of patients had MR $<3^{\text {rd }}$ degree [14]. It is too early to draw definite conclusions. The most recent guidelines of the European Society of Cardiology on the management of heart failure refer to percutaneous treatment of significant MR in patients not qualified for the surgery as a method used to reduce symptoms [15]. However, there are no large randomized trials including a high-risk population and comparing percutaneous treatment to both surgery and conservative treatment as in the PARTNER study in patients with aortic stenosis. It is necessary to assess the durability of the mitral clips in long-term observation and in comparison to cardiac surgery of the mitral valve as well as their assessment in relation to MR etiology. The EVEREST II study included mainly patients with degenerative form of MR and a minority with functional form and moderate risk of surgery. The gap is supposed to be filled by starting studies known as RESHAPE-HF and COAPT including patients at high risk of surgery and a longer observation time. Besides, the anatomic structure and mechanics of the mitral valve are far more complicated in comparison to the aortic valve. In 1 of our patients it was impossible to successfully reduce the valvular regurgitation; however, it is highly probable that implantation of another clip would have improved the effect. As of today, the MitraClip is not a universal and reliable method, but it seems a safe option with low risk of complications. Successive generations of the device and increasing experience may improve the efficacy of this technique and the experience obtained may be necessary for the procedures of transluminal mitral valve implantation - the first procedure of this kind in a human was performed in June 2012 in Copenhagen [16]. As the results of surgery in patients with degenerative form of MR are characterized by high durability [17], it seems probable that the group of patients who will benefit most consists of selected patients with functional ischemic MR including patients after previous revascularization procedures and those with impaired left ventricular function. In these patients surgical treatment in not an attractive option and this is not a small group. Exactly these types of patients (with post-infarction myocardial impairment, after numerous revas- 
cularization procedures) were treated in our center. The suggestions presented above are based on the results of the ACCESS-EUROPE registry and the multicenter observational PERMIT-CARE study, which included 51 patients with symptoms of heart failure, with functional MR and in whom resynchronization therapy was unsuccessful. The use of the MitraClip system in this group of patients improved exercise capacity and the left ventricular ejection fraction and led to reduction of the left ventricular volume in $70 \%$ of patients [18]. It is unknown whether reduction of $M R \leq 2^{\text {nd }}$ degree and lack of annuloplasty, performed routinely during surgical repair, are effective enough, especially in the long term. Long-term observations after cardiac surgery demonstrate that persistence of more than mild MR and lack of annuloplasty are predictors of reoperation, but did not influence the mortality $[19,20]$. Transluminal procedures have became competitive to cardiac surgery due to their less invasive nature and smaller trauma, lack of the need for deep general anesthesia or extracorporeal circulation, and a very short time to mobilization of a patient after the procedure with shorter duration of hospital stay. The word "competition" should be replaced by the word "cooperation". International medical societies emphasize the need for joined consultations and qualification for the optimal method of treatment for the individual patient performed by interdisciplinary teams called Heart Teams and regarding not only the choice of the revascularization modality, but also the method of treatment of valvular heart diseases.

\section{Conclusions}

Percutaneous reduction of mitral regurgitation using the MitraClip system seems to be a safe procedure with low risk of complications. Full assessment of its efficacy and durability as well as full characterization of the target population for whom the MitraClip should be dedicated requires conduction of randomized trials and long-term observation of large groups of patients.

\section{References}

1. Nkomo VT, Gardin JM, Skelton TN, et al. Burden of valvular heart diseases: a population-based study. Lancet 2006; 368: 1005-1011.

2. Vahanian A, Baumgartner H, Bax J, et al. Guidelines on the management of valvular heart disease. The Task Force on the Management of Valvular Heart Disease of the European Society of Cardiology. Eur Heart J 2007; 28: 230-268.

3. lung B, Baron G, Butchart EG, et al. A prospective survey of patients with valvular heart disease in Europe: the Euro Heart Survey on Valvular Heart Disease. Eur Heart J 2003; 24: 1231-1243.

4. Nowicki ER, Birkmeyer NJ, Weintraub RW, et al. Multivariable prediction of in-hospital mortality associated with aortic and mitral valve surgery in Northern New England. Ann Thorac Surg 2004; 77: 1966-1977.

5. Alfieri O, Maisano F, DeBonis M, et al. The edge-to-edge technique in mitral valve repair: a simple solution for complex problems. J Thorac Cardiovasc Surg 2001; 122: 674-681.

6. Feldman T, Wasserman HS, Herrmann HC, et al. Percutaneous mitral valve repair using the edge-to-edge technique: six-month results of the EVEREST Phase I Clinical Trial. J Am Coll Cardiol 2005; 46: 2134-2140.

7. Kalarus Z, Kukulski T, Lekstin A, et al. Methodology and safety of transvascular reduction of severe mitral insufficiency with MitraClip in high-surgical-risk patients - first three cases in Poland. Kardiol Pol 2010; 68: 729-735.

8. Świątkiewicz I, Rychter M. New techniques in cardiology: the role of echocardiography in the classification and monitoring of percutaneous MitraClip system implantation in the treatment of mitral regurgitation. Kardiologia po Dyplomie 2011; 10: 43-53.

9. Feldman T, Foster E, Glower DG, et al. Percutaneous repair or surgery for mitral regurgitation. N Engl J Med 2011; 364: 1395-1406.

10. Whitlow PL, Feldman T, Pedersen WR, et al. Acute and 12-month results with catheter-based mitral valve leaflet repair: the EVEREST II (Endovascular Valve Edge-to-Edge Repair) high-risk study. J Am Coll Cardiol 2012; 59: 130-139.

11. Franzen O, Baldus S, Rudolph V, et al. Acute outcomes of MitraClip therapy for mitral regurgitation in high-surgical-risk patients: emphasis on adverse valve morphology and severe left ventricular dysfunction. Eur Heart J 2010; 31: 1373-1381.

12. Baldus S, Schillinger W, Franzen O, et al. MitraClip therapy in daily clinical practice: initial results from the German transcatheter mitral valve interventions (TRAMI) registry. Eur J Heart Fail 2012; 14: 1050-1055.

13. Tamburino C, Ussia GP, Maisano F, et al. Percutaneous mitral valve repair with the MitraClip system: acute results from a real world setting. Eur Heart J 2010; 31: 1382-1389.

14. Schillinger W, Ray S. Hot Line II: Late Breaking Trials on Interventions. ESC Congress 2012, Munich, Germany.

15. McMurray J, Adamopoulos S, Anker SD, et al. ESC Guidelines for the diagnosis and treatment of acute and chronic heart failure 2012. The Task Force for the Diagnosis and Treatment of Acute and Chronic Heart Failure 2012 of the European Society of Cardiology. Developed in collaboration with the Heart Failure Association (HFA) of the ESC. Kardiol Pol 2012; 70 Suppl II: 101-176.

16. http://www.cardiaq.com/newsreleases.html

17. Johnston DR, Gillinov AM, Blackstone EH, et al. Surgical repair of posterior mitral valve prolapse: implications for guidelines and percutaneous repair. Ann Thorac Surg 2010; 89: 1385-1394.

18. Auricchio A, Schillinger W, Meyer S, et al. Correction of mitral regurgitation in nonresponders to cardiac resynchronization therapy by MitraClip improves symptoms and promotes reverse remodeling. J Am Coll Cardiol 2011; 58: 2183-2189.

19. Suri RM, Schaff HV, Dearani JA, et al. Survival advantage and improved durability of mitral repair for leaflet prolapse subsets in the current era. Ann Thorac Surg 2006; 82: 819-826.

20. Bhudia SK, McCarthy PM, Smedira NG, et al. Edge-to-edge (Alfieri) mitral repair: results in diverse clinical settings. Ann Thorac Surg 2004; 77: 1598-1606. 